\title{
CONTROLE DA EROSÃO EM MARGENS DE CURSOS D'ÁGUA: DAS SOLUÇÕES EMPÍRICAS À TÉCNICA DA BIOENGENHARIA DE SOLOS
}

\section{Riverbank erosion control at streams margin: from empiricism to soil bioengineering technique}

\author{
Francisco Sandro Rodrigues HOLANDA ${ }^{1}$ \\ Arilmara Abade BANDEIRA ${ }^{2}$ \\ Igor Pinheiro da ROCHA ${ }^{3}$ \\ Renisson Neponuceno de ARAÚJO FILHO ${ }^{4}$ \\ Luisa Ferreira RIBEIRO 5 \\ Marcelo Alário ENNES
}

\begin{abstract}
RESUMO
O objetivo deste trabalho foi identificar analiticamente formas de controle da erosão em margens de cursos d'água no Estado de Sergipe, como resultado do empirismo das populações ribeirinhas ou das intervenções por meio de obras civis ou bioengenharia de solos. As áreas estudadas compreendem trechos das margens dos rios São Francisco, Sergipe e Paramopama, localizados nos municípios do trecho sedimentar do baixo São Francisco como Propriá, Santana do São Francisco, Neópolis, Ilha das Flores e Brejo Grande na foz do rio, além de Aracaju e São Cristóvão, respectivamente. A população ribeirinha tem procurado amenizar o processo erosivo por meio do uso de materiais de disponibilidade local e de baixo custo e, o poder público tem implantado enrocamentos nas margens dos rios, além do uso de técnicas de bioengenharia de solos, que protege o talude do rio, proporcionando rápido desenvolvimento da vegetação.
\end{abstract}

Palavras-chave: Populações tradicionais; Rio; Degradação ambiental.

\begin{abstract}
The goal of this paper is to analytically identify river bank erosion control practices in the state of Sergipe, Brazil, adopted by the riverine population or by governmental actions through civil engineering and also by soil bioengineering techniques. The studied sites are located in the margin of the Lower São Francisco River, Sergipe River and Paramopama River in the Municipalities of Propriá, Santana do São Francisco, Neópolis, Ilha das Flores and Brejo Grande at the river mouth, and also in the municipalities of Aracaju and São Cristóvão, respectively. The riverine populations have tried their own solutions in order to control the riverbank's erosion through the use of local low cost materials. On the other hand, riprap has been applied in the riverbank in order to absorb the impact of water waves. The use of soil bioengineering techniques has been motivated by immediate soil protection against erosion, promoting fast revegetation.
\end{abstract}

Keywords: Traditional populations; River; Environmental degradation.

\footnotetext{
1 Professor Adjunto, D.Sc., Universidade Federal de Sergipe. E-mail: fholanda@infonet.com.br.

2 Engenheira Civil, M.Sc., SENAI.

3 Engenheiro Florestal, M.Sc.

4 Acadêmico de Engenharia Florestal, UFS.

5 Bióloga, M.Sc.
} 
HOLANDA, F. S. R. et al. Controle da erosão em margens de cursos d'água: das soluções...

\section{INTRODUÇÃO}

O debate sobre sustentabilidade vem se alargando nas últimas décadas no sentido de romper com perspectivas centradas numa lógica onde as inovações tecnológicas representariam uma fonte ilimitada de soluções para os problemas ambientais. Contrária a essa perspectiva, vários autores apontam para a necessidade de atentar para as dimensões políticas e culturais da problemática da sustentabilidade. Daí a noção de sustentabilidade socioambiental que propõe transformações em um duplo sentido. Ou seja, a problemática da sustentabilidade deve estar associada à preocupação de resolver tanto as desigualdades sociais quanto os problemas ambientais (LEFF, 2007).

As áreas ciliares no estado de Sergipe vêm experimentando grandes transformações na sua paisagem natural promovidas pela erosão, com reflexos não apenas no segmento ambiental, mas também em um amplo espectro socioeconômico. A erosão das margens dos cursos d'água é uma das manifestações mais visíveis do complexo reajustamento da morfologia do canal em busca de um novo equilíbrio dinâmico e das alterações na dinâmica do sistema fluvial, ocorrendo um trabalho contínuo de escavação na base da margem côncava, onde a velocidade é maior, e de deposição na parte convexa (CHRISTOFOLETTI, 1981; GUERRA; CUNHA, 2003). Os processos erosivos ocorrem quando a resultante de todas as forças atuantes sobre o material erodível excede o resultado efetivo de todas as forças que tendem a conservar o material no próprio local (SIMONS, 1982).

A erosão nas margens potencializada ou não pela retirada da mata ciliar, tem se constituído em grave processo de degradação ambiental com rebatimentos nas atividades de navegação e pesca importantes para a sustentabilidade econômica das populações ribeirinhas (HOLANDA et al., 2005).

O avanço dos processos erosivos tem levado à adoção de práticas de controle sejam a partir do empirismo da população ribeirinha ou pelo uso de soluções de engenharia, ou mesmo a bioengenharia de solos. As práticas adotadas pelos ribeirinhos procuram consolidar esse intercâmbio profícuo entre a ciência e as práticas tradicionais (TRIVIÑOS, 1995). O chamado saber ambiental das comunidades tradicionais e seus fundamentos não são, necessariamente, os mesmos do saber ambiental técnico e acadêmico, se apresentando muitas vezes como abrangente e complexo. Na medida em que as características que definem as especificidades socioculturais de uma determinada comunidade não são consideradas devidamente, submetem-se essas singularidades ao campo das soluções técnicas (TEIXEIRA, 2005).

Seja naturalmente, ou seja pela mão do homem, os rios estão sujeitos a desequilíbrios que podem ser mitigados ou evitados por meio de obras adequadas (BRANDÃO, 2001). A colocação de uma carga de pedras, ou enrocamentos, que possa reter a massa do terreno, mas que permita a drenagem da água, é um dos métodos utilizados para controle dos desmoronamentos (PENTEADO, 1983). Os enrocamentos são obras de engenharia usadas para o controle da erosão, sendo um, entre vários, dos métodos de proteção das margens dos rios, também chamado de RSP (Rock Slope Protection) ou riprap.

Outra técnica usada para conter erosões em margens de cursos d'água, e que ganha espaço pela menor agressividade no que diz respeito às alterações paisagísticas, é a bioengenharia de solos, que consiste no uso de elementos biologicamente ativos, em obras de estabilização de solo e de sedimentos, conjugados com elementos inertes como concreto, madeira, ligas metálicas, polímeros, e mantas confeccionadas com fibras vegetais, que são chamadas de geotêxteis ou biomantas (GRAY; SOTIR, 1996).

O objetivo deste trabalho, é discutir as formas de controle da erosão em margens de cursos d'água no Estado de Sergipe, sejam aquelas utilizadas pelas populações ribeirinhas fruto do seu empirismo, ou resultante de intervenções com obras civis ou uso da bioengenharia de solos.

\section{ÁREAS DE ESTUDO}

Neste estudo foram levantadas informações referentes às margens do rio São Francisco no seu baixo curso, abrangendo os municípios de Propriá, Santana do São Francisco, Neópolis, Ilha das Flores e Brejo Grande na foz do rio, assim como os municípios de Aracaju abrangendo as margens do rio Sergipe (Bacia hidrográfica de mesmo nome), e no município de São Cristóvão nas margens do rio Paramopama (Bacia hidrográfica do Rio Vaza-Barris), no Estado de Sergipe (Figura 1).

O rio São Francisco é o mais longo rio totalmente brasileiro, e é a principal fonte de água de superfície para a Região Nordeste, com seu baixo curso compreendendo $7.276,3 \mathrm{~km}^{2}$, ou seja, $33 \%$ da área do Estado de Sergipe. Esse estudo foi realizado em extensão de margem de $40 \mathrm{~km}$ e largura canal superior a $500 \mathrm{~m}$, 
HOLANDA, F. S. R. et al. Controle da erosão em margens de cursos d'água: das soluções...

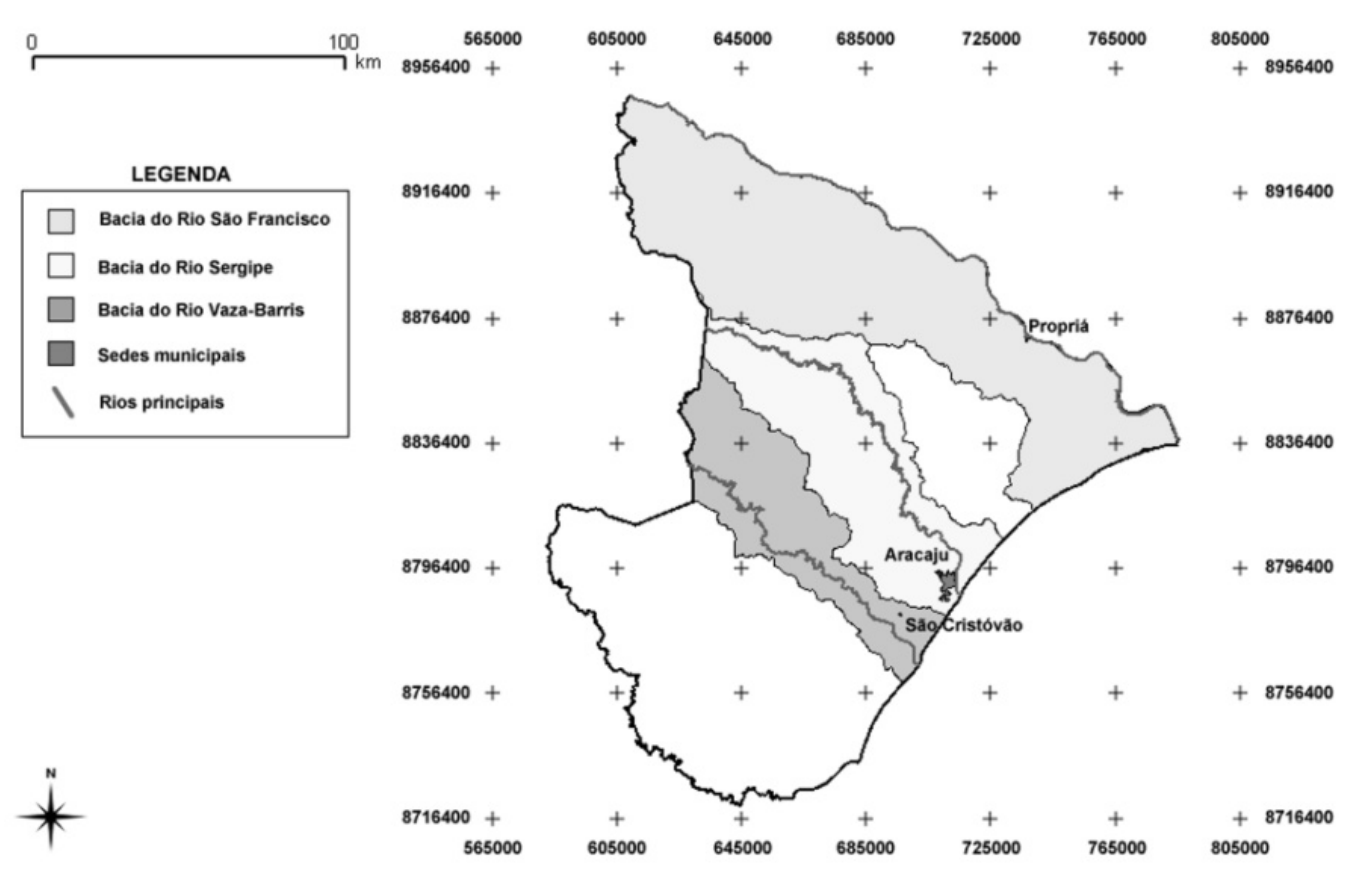

FIGURA 1 - LOCALIZAÇÃO DAS ÁREAS DE ESTUDO

correspondente aos Perímetros Irrigados de Propriá, Cotinguiba-Pindoba e Betume, ocupados principalmente com a rizicultura e piscicultura, além de fruticultura, se estendendo desde a cidade de Propriá até a foz do rio. Esse é considerado um trecho sedimentar e apresenta padrão de canal anastomosado (CASADO et al., 2002).

A sub-bacia hidrográfica do rio Paramopama está localizada na região litorânea do sul do Estado de Sergipe, no município de São Cristóvão, e compõe a bacia hidrográfica do rio Vaza-Barris, sendo um dos seus principais afluentes. A área estudada neste rio está inserida no domínio morfoestrutural da Bacia Sedimentar Sergipe-Alagoas, trecho onde o rio corre em vales normais encaixados no relevo colinoso dos sedimentos do Grupo Barreiras, e despeja suas águas em um braço de maré na margem esquerda do estuário do rio Vaza Barris.

O rio Sergipe nasce próximo à fronteira do Estado de Sergipe com a Bahia e segue cerca de $210 \mathrm{Km}$ em direção ao Oceano Atlântico, onde desemboca na praia de Atalaia Nova, perto da cidade de Aracaju. Trata-se da principal bacia hidrográfica de Sergipe, com área da de $3.673 \mathrm{Km}^{2}$, ocupando aproximadamente $16,7 \%$ da área do Estado (HOLANDA NETO et al., 2000).

Em relação ao sistema estuarino, destaca-se o importante papel dos mangues e restingas no controle da erosão e na retenção de nutrientes provenientes, tanto de montante, como do ciclo das marés.

\section{OS PROCESSOS EROSIVOS NAS MARGENS DOS RIOS}

No Baixo São Francisco a erosão nos taludes do rio vem contribuindo no incremento da carga de fundo e provoca a destruição da área ripária, outrora ocupada pela vegetação ciliar, e hoje ocupada com agricultura de sequeiro ou perímetros irrigados. Face ao seu rápido avanço vem limitando ou inviabilizando o uso do solo. Os movimentos de massa ocorridos nos taludes marginais, se destacam como agentes atuantes na evolução do processo erosivo trazendo implicações sócioeconômicas resultantes da perda de áreas produtivas. Percebe-se um trabalho contínuo de escavação na margem côncava, onde a velocidade é maior, e de deposição na margem convexa, local de menor velocidade (CRISTOFOLETTI, 1981), facilitados por uma margem desmatada composta por um talude de material de muito baixa coesão.

No rio Paramopama os fatores geomorfológicos como geometria do canal, o seu grau de sinuosidade, as formas deposicionais presentes no leito, a morfologia 
HOLANDA, F. S. R. et al. Controle da erosão em margens de cursos d'água: das soluções...

das seções transversais, assim como a composição granulométrica das camadas de solo do talude, estão entre aqueles que exercem uma forte influência sobre a erosão marginal. Naquele curso d'água a erosão nas margens não permite que a necessária diversidade de espécies vegetais se fixe ao solo, tornando o ambiente altamente degradado, possibilitando somente o desenvolvimento de espécies da família Gramineae em forma de manchas esparsas, não exercendo a função de fixação do talude, e levando à ocorrência de movimentos de massa de solo.

Interposto entre depósitos quaternários, o estuário do Rio Sergipe, definido em função dos níveis médios de penetração da maré e ocorrência de manguezal, abrange uma extensão de 44 km (ARAÚJO, 2007). Uma feição bastante comum é evidenciada com as marcas de espraiamento de ondas deixadas durante o refluxo. A variabilidade na direção e intensidade dos ventos na área da bacia costeira implica em constantes modificações no perfil praial, motivo pelo qual altera-se o equilíbrio da praia tornando-o apenas temporário, com o balanço entre erosão e deposição sujeitas a ciclos.

\section{AS PRÁTICAS EMPÍRICAS DE CONTROLE DA EROSÃO MARGINAL}

Recuperar as margens de um curso d'água submetido a processos erosivos é um trabalho bastante complexo devido à sua dinâmica hidrosedimentológica, especialmente margens desmatadas e com solos pouco coesivos, onde o processo de erosão é mais rápido. Em margens de rios de grande, médio ou pequeno porte, o controle da erosão assume peculiaridades que devem considerar aspectos geomorfológicos, geotécnicos e sociais face à forma de uso e ocupação dessas áreas, pelas populações locais. Geralmente é preciso conciliar os conhecimentos empíricos de tecnologia das áreas da engenharia civil ou bioengenharia de solos para a adequada estabilização das margens.

No Baixo São Francisco, assim como na margem do Rio Sergipe foi possível identificar práticas empíricas de controle da erosão das margens, como registro de alternativas adotadas pela população local como forma de proteção das margens ocupadas por agroecossistemas produtivos. Independentemente da atuação dos órgãos públicos no controle da erosão, a população ribeirinha, preocupada com o avanço das águas do rio sobre suas terras, tem procurado amenizar a degradação das suas terras por meio de soluções que utilizem materiais de baixo custo ou mesmo que compõem descartes de uso cotidiano. Alguns dos materiais utilizados têm sido paIha de coqueiro, sacos de areias, borracha de câmaras de ar entrelaçada e pneus usados (Figura 2). Embora sejam tentativas que buscam resolver o problema que demanda uma solução imediata é importante destacar os consequentes riscos ambientais. Fenner; Clarke (2003) apresentam resultados que mostram que o fator limitante para o uso de pneus em situações como estas é a liberação de metais pesados como cádmio, níquel e zinco.
A

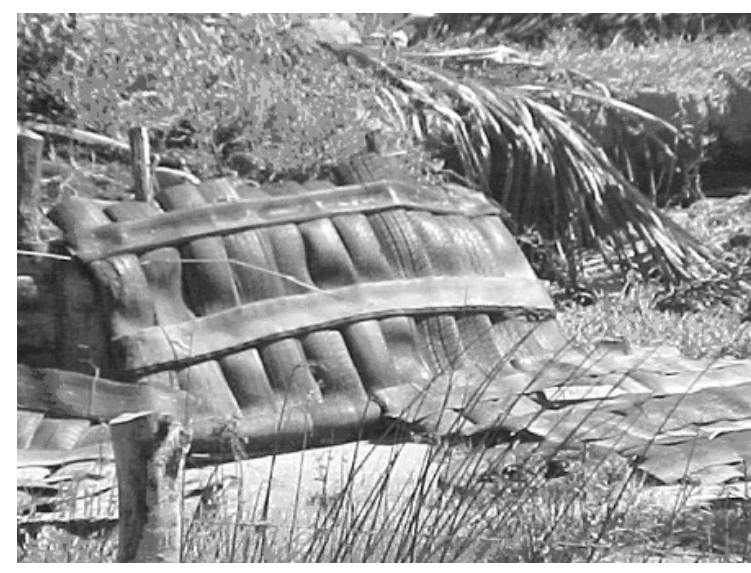

B

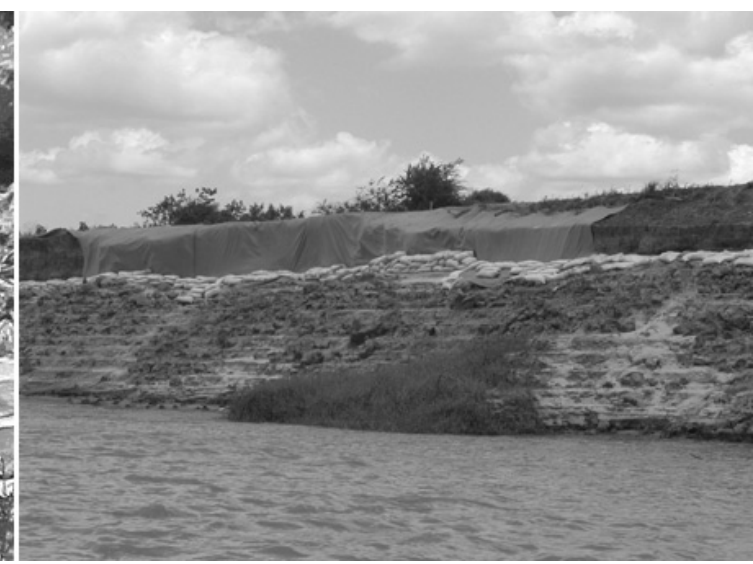

FIGURA 2 - CONTENÇÃO DOS TALUDES MARGINAIS: A) BORRACHA DE CÂMARA DE AR TRANÇADA E PNEUS VELHOS; B) SACOS DE AREIA, NAS PROXIMIDADES DO MUNICÍPIO DE BREJO GRANDE/SE (MARÇO/2004) 
HOLANDA, F. S. R. et al. Controle da erosão em margens de cursos d'água: das soluções...

A observância dessas experiências conduzidas pelas populações tradicionais, mesmo sem prévio planejamento vem contribuindo para o avanço da compreensão sobre a complexidade da questão da sustentabilidade e suas implicações sociais e culturais. A observação de tais práticas e o contato com essas populações contribuem para a compreensão da dinâmica fluvial e podem ser incorporadas pelo campo acadêmico e científico por meio do desenvolvimento de novas abordagens teóricas e metodológicas. O etnoconhecimento é um exemplo que resulta dos esforços dos estudiosos das relações entre sociedade e natureza em dialogar com o conhecimento de grupos tradicionais e/ou locais de maneira a não depreciá-lo como inferior e/ou inválido (FREY, 2001). Cabe a realização de estudos analíticos, buscando a identificação da eficiência das práticas adotadas, na busca da valorização do conhecimento não formal, e provável adaptação numa perspectiva metodológica formal, possível de ser replicada em situações similares e que demandam mitigação de problemas ambientais como o controle da erosão.

\section{A UTILIZAÇÃO DOS ENROCAMENTOS NOS TALUDES NO BAIXO CURSO DOS RIOS SÃO FRANCISCO E SERGIPE}

Como ocorre nos grandes rios pelo mundo, os enrocamentos ou rip-rap vêm sendo implantados, desde a década de 80, ao longo das margens dos rios brasileiros e não fugindo à regra, nos rios sergipanos também, como alternativos para conter o processo de erosão marginal. Para contornar o problema da baixa coesão dos solos aluviais das margens dos rios, normalmente Neossolos Flúvicos ${ }^{6}$, tem sido trabalhado nos taludes locais, material granular com diâmetro médio de 70 $\mathrm{cm}$. Este material não só retém as partículas que foram arrastadas pela erosão subterrânea como absorve o impacto das ondas sobre a face do barranco, evitando o solapamento de sua base.

Perpendicularmente à margem do baixo curso do rio São Francisco foram construídos espigões nos anos de 1985, 1986 e 2001, também compostos de material granular, que afastaram o fluxo da corrente da margem direita do canal fluvial, diminuindo a ação da turbulência e da velocidade da água no processo de erosão. Os espigões têm a finalidade de impedir que as ondas geradas pelos ventos atinjam diretamente a base do barranco, provocando solapamento, e criam uma zona de deposição de sedimentos à jusante, visando a formação de uma praia estável (Figura 3). O enrocamento do barranco é executado para absorver o impacto das ondas sobre a base desses taludes marginais.

O enrocamento somente da base do barranco tem sido a solução de engenharia mais comumente adotada, para conter os movimentos de massa nos taludes do Baixo São Francisco, assim como o crescente assoreamento na calha do rio, alterando a sua feição, uma vez que o avanço da erosão em alguns trechos da margem
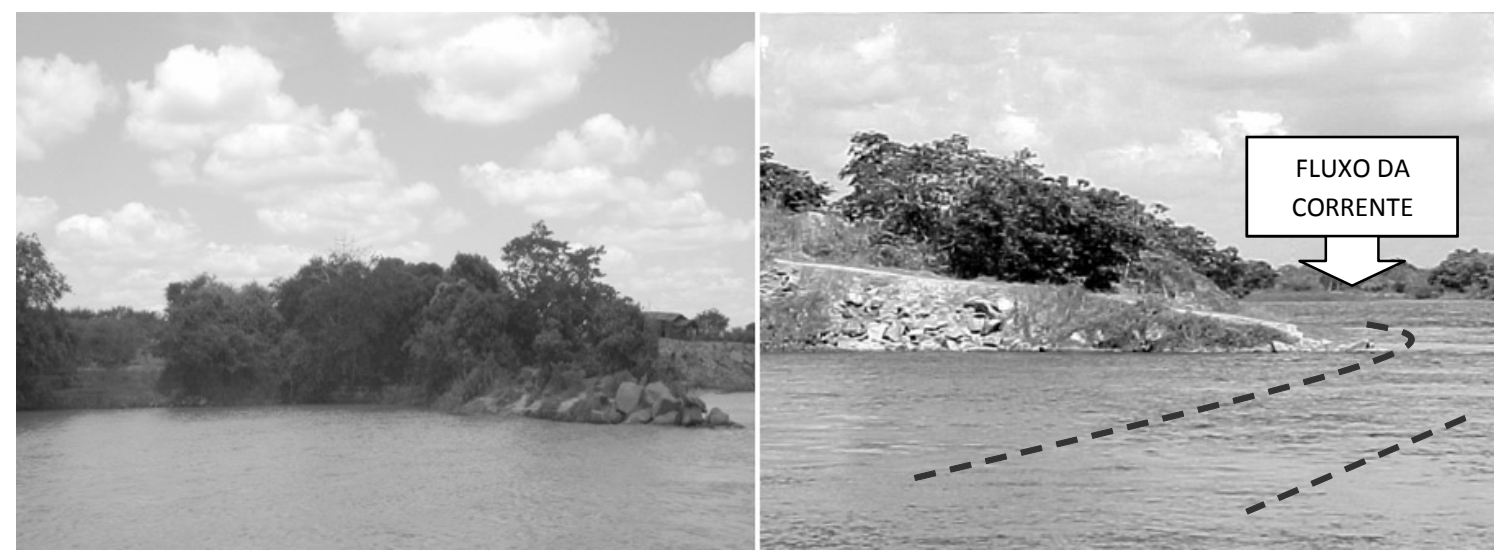

FIGURA 3 - ESPIGÕES CONSTRUÍDOS NO PERÍMETRO IRRIGADO COTINGUIBA-PINDOBA EM 1985 E 2001, RESPECTIVAMENTE (MARÇO/2007)

6 Neossolos Flúvicos (Solos Aluviais) derivados de sedimentos aluviais com horizonte A assente sobre horizonte C constituído de camadas estratificadas, sem relação pedogenética entre si, predominante nas margens de rios. 
HOLANDA, F. S. R. et al. Controle da erosão em margens de cursos d'água: das soluções...

pode chegar a $30 \mathrm{~m} / \mathrm{ano}$ (CASADO et al., 2002).

No primeiro espigão construído no Baixo São Francisco em 1985, na margem direita do canal fluvial é possível identificar que com a sua implantação, formou-se uma área onde os sedimentos estão sendo depositados, evitando que as ondas atinjam a base do talude e o consequente solapamento. Verifica-se também que a margem se encontra estabilizada e recoberta por densa vegetação (Figura 4a), apresentando também faixa de praia fluvial (Figura 4), demonstrando que mesmo em condições não adequadas, é possível o desenvolvimento de espécies vegetais, que fazem diminuir o impacto visual na paisagem, drasticamente modificada pela implantação do enrocamento.

A

B

C
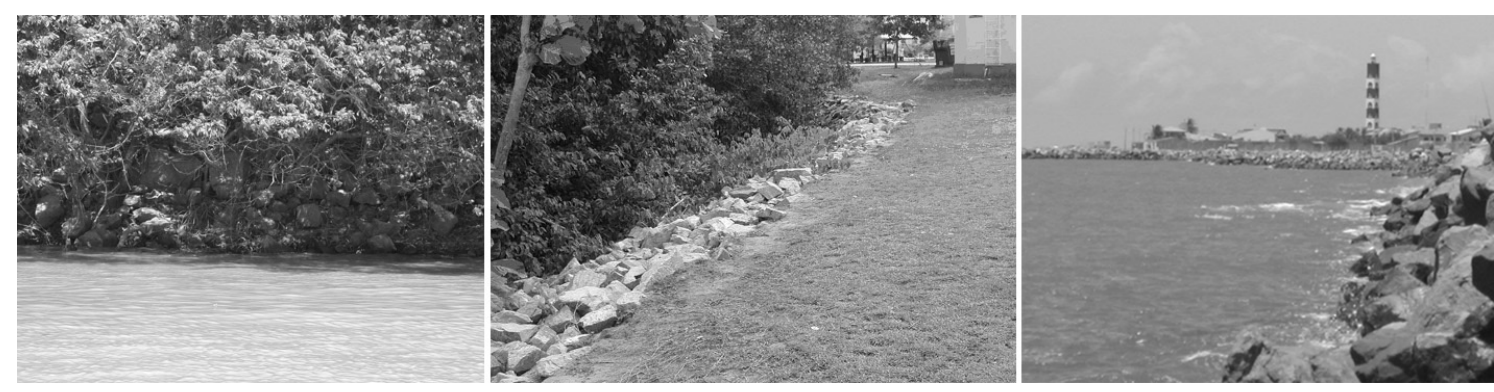

FIGURA 4 - USO DO ENROCAMENTO: A) TALUDE ESTABILIZADO NO PERÍMETRO IRRIGADO CONTIGUIBA-PINDOBA, EM PROPRIÁ; B) MARGEM DO RIO SERGIPE, EM ARACAJU; C) BAIRRO COROA DO MEIO, EM ARACAJU (MARÇO/2007)

Quanto ao estado de conservação dos trechos com enrocamento, percebe-se que grandes extensões encontram-se estabilizados e até mesmo naturalmente revegetadas, embora ocorra solapamento na base, levando à questionamentos sobre a completa eficiência destas obras no controle da erosão.

O enrocamento tem sido também utilizado na contenção da erosão na margem do rio Sergipe, bem próximo ao estuário, localizado na Cidade de Aracaju, para conter o fluxo e refluxo das ondas nas margens do rio nos bairros Coroa do Meio e Atalaia Nova e na zona estuarina associada (Figuras 4b e 4c). No estuário do rio Sergipe, na sua margem direita, o enrocamento foi construído para conter o avanço das águas do rio sobre uma área que antes era praia e que, depois de aterrada, foi transformada numa área de lazer, e tem cumprido com eficiência o seu papel na contenção das águas, no período de marés altas. O enrocamento construído na região do bairro Coroa do Meio, no estuário da margem direita do rio Sergipe, vem passando por constante manutenção, com a reposição do material granular, explicada pela variação diária das marés e força de fluxo e refluxo das ondas, que têm comprometido a durabilidade da estrutura.

\section{O USO DA BIOENGENHARIA NO CONTROLE DA EROSÃO MARGINAL}

O uso de biomantas ou geotêxteis em associação com retentores de sedimentos, como apresentados na Figura 5, tem o objetivo de estabilizar o talude marginal a partir da associação com espécies vegetais (arbustivas e/ou gramíneas) de desenvolvimento rápido, propiciando a formação de um ambiente para o desenvolvimento de vegetação ripária obedecendo ao modelo de sucessão secundária. A escolha pela utilização do geotêxtil no Baixo São Francisco e no rio Paramopama foi motivada pelas vantagens como a proteção imediata do solo contra a erosão, a sua degradação programável, além de proporcionar rapidez no processo de revegetação.

No barranco da margem do baixo curso do Rio São Francisco as faixas de geotêxtil foram dispostas transversalmente à margem do rio, a partir da superfície do solo no alto do barranco, até sua parte mais baixa. $\mathrm{Na}$ linha d'água foram instalados retentores de sedimentos, que são constituídos de fibras vegetais, envolvidos por malha de polipropileno. 
A

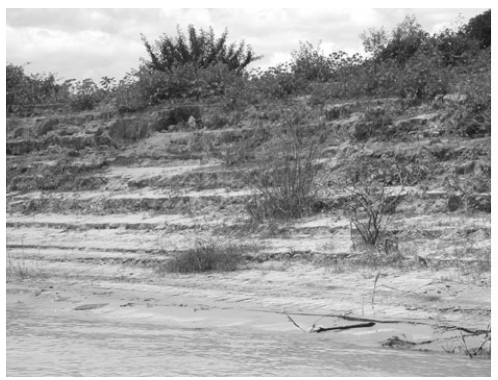

B

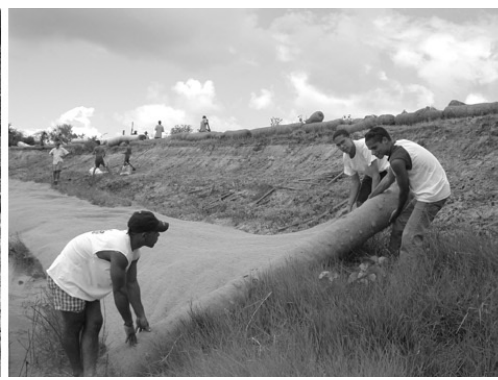

C

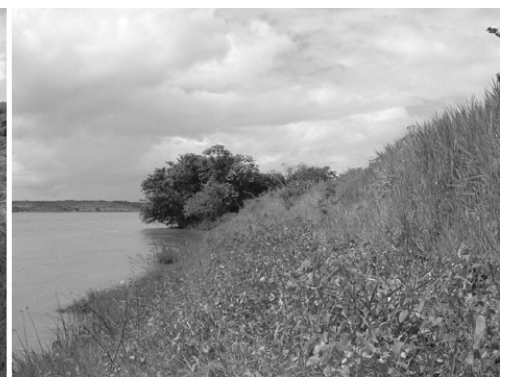

FIGURA 5 - IMPLANTAÇÃO DA BIOENGENHARIA DE SOLOS NO TALUDE MARGINAL DO RIO SÃO FRANCISCO, NO PERÍMETRO IRRIGADO COTINGUIBA-PINDOBA: A) TALUDE ANTES DA INSTALAÇÃO; B) INSTALAÇÃO DO GEOTÊXTIL; C) TALUDE 60 DIAS APÓS A IMPLANTAÇÃO (PERÍODO DE JULHO/2004 A MARÇO/2006)

Os resultados obtidos ao longo do período de avaliação da eficiência da técnica de bioengenharia de solos (Figura 6) mostram a importância dos elementos vivos e inertes na proteção física do talude contra os efeitos da erosão marginal (HOLANDA et al., 2008). O geotêxtil contribuiu para a estabilização do talude e mostrou eficiência no controle da erosão das margens no período avaliado, perceptível pela pequena varia- ção no perfil transversal inicial em comparação com a situação dois anos depois. No entanto, o talude sem proteção da bioengenharia, que inicialmente apresentava declividade média de $33 \%$, passou a se mostrar verticalizado levando em consequência, os frequentes movimentos de massa com queda de grandes blocos a partir do solapamento da base, com expressiva alteração no perfil transversal.
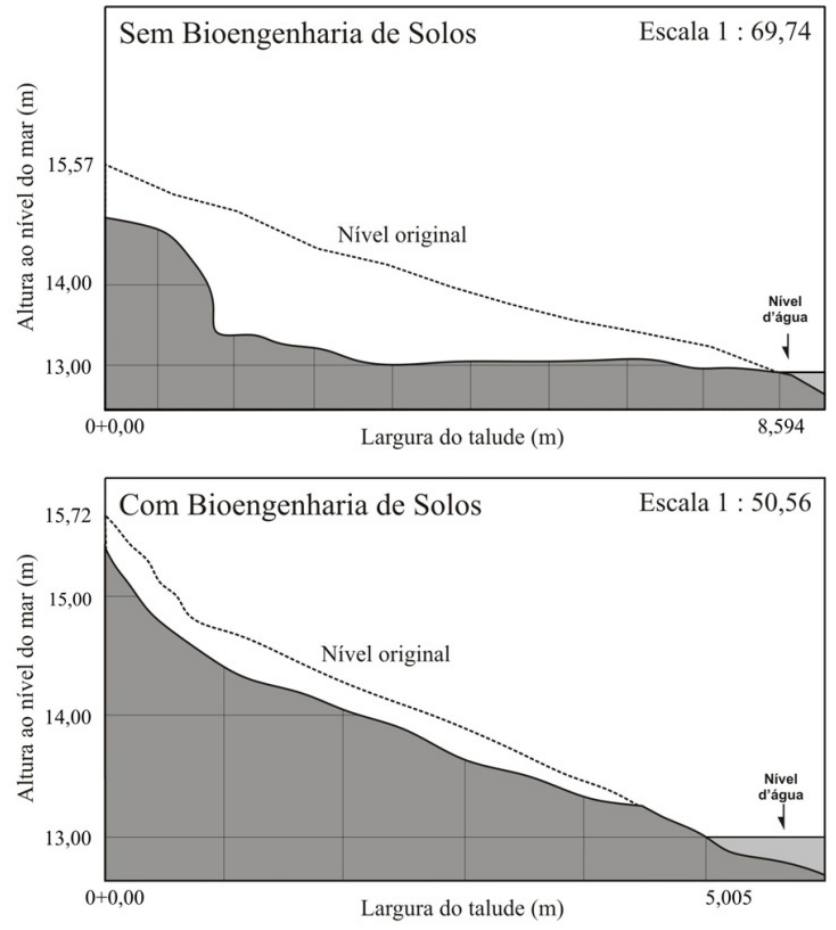

FIGURA 6 - COMPARATIVO ENTRE OS TRATAMENTOS COM BIOENGENHARIA DE SOLOS E SEM BIOENGENHARIA DE SOLOS (PERÍODO DE SETEMBRO/2004 A MARÇO /2006) 
HOLANDA, F. S. R. et al. Controle da erosão em margens de cursos d'água: das soluções...

A técnica da bioengenharia de solos por meio do uso dos seus componentes, sejam materiais degradáveis ou inertes, conjugados com retentores de sedimentos (Ex. rio São Francisco) ou colchões-reno (Ex. rio Paramopama) diminui os efeitos do solapamento na base do talude, para o controle de desmoronamento sucessivos de blocos de solo, pois mesmo com o solapamento da base, a técnica aumenta a resistência do bloco dificultando o imediato cisalhamento da estrutura do solo (Figura 7).
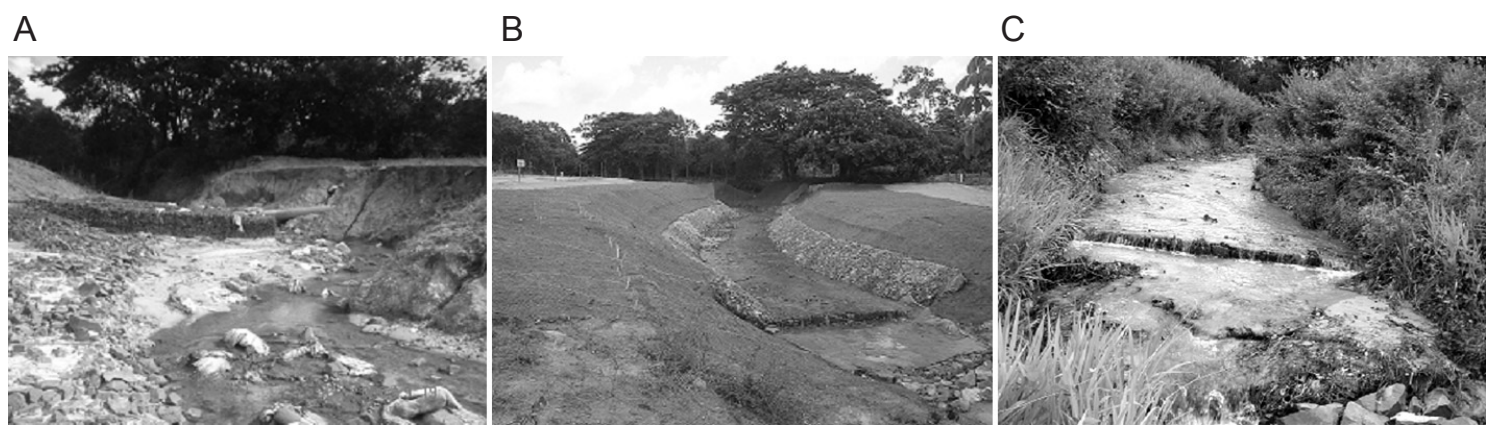

FIGURA 7 - FASES DA IMPLANTAÇÃO DA BIOENGENHARIA NAS MARGENS DO RIO PARAMOPAMA : A) MARGEM ERODIDA; B) IMPLANTAÇÃO DO GEOTÊXTIL E COLCHÃO-RENO; C) MARGEM REVEGETADA (PERÍODO DE JANEIRO/2007 A MARÇO/2008)

O sistema radicular da cobertura vegetal proporciona uma maior força de coesão e melhor resistência ao cisalhamento, conservando o perfil transversal e a declividade do talude. No Baixo São Francisco a estabilização do talude da margem representa primordialmente a possibilidade de recuperação da vegetação ciliar, uma vez que o desenvolvimento da vegetação se dá numa taxa superior à velocidade dos processos erosivos. Como consequência do controle da erosão, é esperada uma menor taxa de sedimentação traduzida na forma de diminuição do assoreamento da calha do rio.

\section{CONSIDERAÇÕES FINAIS}

A eficiência das técnicas utilizadas no controle da erosão é variável em função da feição dos taludes a serem estabilizados, assim como da dinâmica natural do rio, podendo ser também alteradas pelas ações antrópicas.

As práticas empíricas dos ribeirinhos reconhecidamente apresentam um importante valor para o controle da erosão, no que diz respeito à aplicação dos conhecimentos oriundos da sua vivência na margem do rio. Porém constata-se, que a falta de planejamento e conhecimento necessário sobre os riscos para o meio ambiente, tem resultado na ineficácia no controle da erosão marginal, funcionando apenas provisoriamente para impedir que o avanço das águas sobre o talude continue a carrear o solo para o canal do rio.
O enrocamento promove a estabilização do talude do rio, em situações de intenso trabalho erosivo na margem, seja pela baixa coesão do solo constituinte do talude, seja pela proximidade do canal principal ou fluxo mais intenso da água à margem do rio. Ocorrem várias situações em que somente essa técnica pode promover o controle da erosão, embora se apresente de alto custo, normalmente somente conduzido com recursos governamentais, em situações que colocam em risco as terras de Perímetros Irrigados públicos ou povoamentos situados na margem dos rios, ou mesmo nas margens de reservatórios.

A bioengenharia de solos se apresenta como uma das formas mais eficazes na contenção da erosão, pois pode promover o reforço do talude sem necessidade de cálculos estruturais complexos, além de possibilitar o emprego de matéria prima disponível na região necessária para a confecção dos biotêxteis, como fibras de côco, sisal, etc. As limitações residem no fato de que essa técnica, que possibilita o desenvolvimento da vegetação ciliar, à medida que, por meio da proteção do talude realiza a sua estabilização, não pode ser implantada em qualquer situação. Taludes muito inclinados, ou mesmo muito altos, assim como de composição granulométrica de baixa coesão, podem limitar o uso da técnica. Margens côncavas em que o fluxo mais intenso de água no canal do rio se apresenta muito próximo da margem, resultante da dinâmica natural do rio, se apresentam como outro importante fator limitante da adoção dessa técnica. 
HOLANDA, F. S. R. et al. Controle da erosão em margens de cursos d'água: das soluções...

\section{REFERÊNCIAS}

ARAÚJO, H. M. Relações Socioambientais na Bacia Costeira do Rio Sergipe. Tese (Doutorado em Geografia) - Universidade Federal de Sergipe, São Cristóvão, 2007.

BRANDÃO, J. L. B. Obras de regularização do leito. Tese (Doutorado em Engenharia Civil) - Escola Politécnica da Universidade de São Paulo, São Paulo, 2001.

CASADO, A. P. B.; HOLANDA, F. S. R.; ARAUJO FILHO, F. A. G.; YAGUIU, P. Evolução do processo erosivo na margem direita do rio São Francisco. Revista Brasileira de Ciência do Solo, Viçosa, v. 26, n. 1, p. 231-239, 2002.

CHRISTOFOLETTI, A. Geomorfologia fluvial. Volume I - O canal fluvial. São Paulo: Edgard Blücher, 1981.

FENNER, R. A.; CLARKE, K. Environmental and structural implications for the re-use of tyres in fluvial and marine construction projects. Water and Environment Journal, London, v. 17, n. 2, p. 99-105, 2003.

FREY, K. A dimensão político-democrática nas teorias de desenvolvimento sustentável e suas implicações para a gestão local. 2001. Disponível em:<http://www.scielo.br.pdf/asoc/ n9/16878.pdf>. Acesso em: 6/4/2008.

GRAY, D. H.; SOTIR, R. Biotechnical and Soil Bioengineering Slope Stabilization. New York: John Wiley,1996.

GUERRA, A. J. T.; CUNHA, S. B. (Org.). Geomorfologia: uma atualização de bases e conceitos. Rio de Janeiro: Bertrand Brasil, 2003.

HOLANDA, F. S. R.; SANTOS, L. G. C.; SANTOS, C. M. S.; CASADO, A. P. B.; PEDROTTI, A. Riparian fragments affected by bank erosion in the Lower São Francisco River, Northeastern Brazil. Revista Árvore, Viçosa, v. 29, n. 2, p. 148-152, 2005.

HOLANDA, F. S. R.; ROCHA, I. P.; OLIVEIRA, V. S. Estabilização de taludes marginais com técnicas de bioengenharia de solos no Baixo São Francisco. Revista Brasileira de Engenharia Agrícola e Ambiental, Campina Grande, v. 12, n. 6, p. 570-575, 2008.

HOLANDA NETO, J.; CANTONHEDE, V. S. M.; BARRETO, I. M. C. B. N., MARCONDES, S. F. Programa Estadual de Apoio à Gestão Participativa dos Recursos Hídricos. Aracaju: SEPLANTEC / SRH, 2000.

LEFF, E. Globalização, ambiente e sustentabilidade do desenvolvimento. In: - Saber ambiental: sustentabilidade, racionalidade, complexidade e poder. 5. ed. Petrópolis: Vozes, 2007.

PENTEADO, M. M. Fundamentos de Geomorfologia. 3. ed. Rio de Janeiro: Secretaria de Planejamento da Presidência da República. Fundação Instituto Brasileiro de Geografia e Estatística - IBGE, 1983.

SIMONS, L. I.; ASSOCIATES. Engineering Analysis of Fluvial Systems. Fort Collins: Simons, LI \& Associates, 1982.

TEIXEIRA, C. O. Desenvolvimento sustentável em unidade de conservação: a "naturalização" do social. Revista Brasileira de Ciências. Sociais, São Paulo, v. 20, n. 59, p. 51-66, 2005.

TRIVIÑOS, A. N. S. Introdução e pesquisa em ciências sociais: a pesquisa quantitativa em educação. São Paulo: Atlas, 1995. 